\title{
Simultaneous observations of a Mesospheric Inversion Layer and turbulence during the ECOMA-2010 rocket campaign
}

\author{
A. Szewczyk ${ }^{1}$, B. Strelnikov ${ }^{1}$, M. Rapp ${ }^{1, *}$, I. Strelnikova ${ }^{1}$, G. Baumgarten ${ }^{1}$, N. Kaifler ${ }^{1}$, T. Dunker ${ }^{2}$, and U.-P. Hoppe ${ }^{3}$ \\ ${ }^{1}$ Leibniz Institute of Atmospheric Physics at the Rostock University, 18225 Kühlungsborn, Germany \\ ${ }^{2}$ University of Troms $\varnothing$, Department of Physics and Technology, 9037 Troms $\varnothing$, Norway \\ ${ }^{3}$ University of Oslo, Department of Physics, 0316 Oslo, Norway \\ *now at: German Aerospace Center Institute of Atmospheric Physics (IPA), Oberpfaffenhofen, 82234 Wessling, Germany
}

Correspondence to: A. Szewczyk (szewczyk@iap-kborn.de)

Received: 4 September 2012 - Revised: 13 February 2013 - Accepted: 8 March 2013 - Published: 3 May 2013

\begin{abstract}
From 19 November to 19 December 2010 the fourth and final ECOMA rocket campaign was conducted at Andøya Rocket Range $\left(69^{\circ} \mathrm{N}, 16^{\circ} \mathrm{E}\right)$ in northern Norway. We present and discuss measurement results obtained during the last rocket launch labelled ECOMA09 when simultaneous and true common volume in situ measurements of temperature and turbulence supported by ground-based lidar observations reveal two Mesospheric Inversion Layers (MIL) at heights between 71 and $73 \mathrm{~km}$ and between 86 and $89 \mathrm{~km}$. Strong turbulence was measured in the region of the upper inversion layer, with the turbulent energy dissipation rates maximising at $2 \mathrm{~W} \mathrm{~kg}^{-1}$. This upper MIL was observed by the ALOMAR Weber Na lidar over the period of several hours. The spatial extension of this MIL as observed by the MLS instrument onboard AURA satellite was found to be more than two thousand kilometres. Our analysis suggests that both observed MILs could possibly have been produced by neutral air turbulence.
\end{abstract}

Keywords. Meteorology and atmospheric dynamics (Middle atmosphere dynamics; Turbulence; Waves and tides)

\section{Introduction}

Since first observed by Schmidlin (1976), temperature inversion layers have been routinely observed in the mesosphere and lower thermosphere (MLT). A recent review of both theory and observations has been provided by Meriwether and Gerrard (2004). These authors have pointed out that despite of the considerable progress that has been made in recent years the formation mechanisms of mesospheric inversions remain poorly understood. Numerous observations show that temperature inversions are often associated with a near adiabatic lapse rates above the inversion layer (Whiteway et al., 1995; Duck et al., 2001), which is clearly indicative of turbulence activity in those regions. However, numerical simulations showed that only vigorous turbulence revealing heating rates of $\sim 10 \mathrm{~K} \mathrm{~h}^{-1}$ is capable of producing temperature inversions (Liu et al., 2000). Such strong turbulence, however, has rarely been observed (see, e.g., Lübken, 1997; Lübken et al., 2002) in contrast to the temperature inversion layers, which are common phenomena.

A common tool to study temperature inversion layers experimentally in the MLT region is lidar observations (e.g., Hauchecorne and Chanin, 1980). The advantage of the lidar measurements is that they deliver continuous (or at least long duration) observation of the temperature field and allow to distinguish between signatures of (short-lived) strong gravity waves and (long-lived) temperature inversions that both create similar signatures in a single altitude-profile. However, this technique does not allow to measure turbulence parameters directly and must rely on indirect information (such as the lapse rate) or numerical simulations for this particular purpose (see e.g., Whiteway et al., 1995; Liu et al., 2000).

Making use of in situ measurements in the MLT, i.e., employing sounding rockets, it is possible to directly measure both temperature and turbulence parameters simultaneously and in the same volume.

In this paper, we present a case study of a temperature field measured in the MLT region during the ECOMA 2010 sounding rocket campaign (see Rapp et al., 2011, for a project overview and payload description). Temperature and 
turbulence profiles were measured in situ using the CONE instrument on-board the ECOMA payload. The both temperature and turbulence parameters are derived from the same neutral density data. Also, the ALOMAR RMR- and Nalidars were continuously operated whenever weather permitted, yielding among other things, continuous temperature measurements near the launch site and several hours before and after the launch time. Additionally, we analysed the data from the Microwave Limb Sounder (MLS) experiment on the Aura satellite which overpassed the launch area around the rocket launch time, to investigate spatial variability of the temperature field.

The MIL in this paper is defined as the region in the mesosphere with continuous, positive temperature gradient. Therefore, it does not include the layer above it.

In the following, we first introduce the various experimental methods considered in this study (Sect. 2). Then we present temperature measurements which were obtained with in situ, ground-based, and satellite techniques (Sect. 3). This is completed with a presentation and subsequent discussion of the in situ turbulence measurements and its connection to the temperature field (Sect. 4) and our final conclusions are presented in Sect. 5.

\section{Measurement techniques}

In the present work, we analyse data obtained simultaneously by four different measurement techniques during the ECOMA-2010 sounding rocket campaign (see more details on the campaign in Sect. 3). Namely, the in situ measurements conducted with an ionization gauge onboard the ECOMA sounding rocket, the ground-based lidar and radar measurements, and the satellite observations.

\subsection{In situ measurements}

All the ECOMA payloads were equipped with the CONE (COmbined sensor for Neutrals and Electrons) instrument (Giebeler et al., 1993) to measure density and temperature of neutral air with very high spatial resolution. The CONE is basically an ionization gauge surrounded by a shielding grid and a fixed biased electrostatic probe. Making use of laboratory calibrations and aerodynamic corrections for the density, CONE measurements yield absolute neutral air densities in height range from 70 to $110 \mathrm{~km}$. Assuming hydrostatic equilibrium by integrating the measured densities the density profile can be converted to a temperature profile with the temperature error of $\pm \sim 3 \mathrm{~K}$ (Rapp et al., 2001, 2002). Furthermore, the CONE measures neutral air density with very high spatial resolution $(\sim 10 \mathrm{~cm}$ at $90 \mathrm{~km})$ and precision (better than $0.1 \%$ ). Thus, CONE measurements are capable to resolve small-scale structures in neutral air density which are created by neutral air turbulence. The turbulence energy dissipation rate is derived based on spectral analy- sis of measured neutral density fluctuations as introduced by Lübken (1992) and Lübken (1997) and extended by Strelnikov et al. (2003). That is, the in situ measurements with CONE yield temperature and turbulence profiles in exactly the same atmospheric volume. CONE was mounted on the rear deck of the ECOMA payload and, therefore, was in a favourable aerodynamic condition (i.e., facing the ram direction) during the downleg part of the trajectory (Rapp et al., 2001).

\subsection{Lidars}

Two ground-based lidars were continuously operated at the Arctic Lidar Observatory for Middle Atmosphere Research (ALOMAR) located on the northern Norwegian island Andøya throughout the entire ECOMA campaign whenever weather conditions permitted.

The ALOMAR Weber sodium (Na) lidar is a resonance fluorescence lidar $\left(69^{\circ} \mathrm{N}, 16^{\circ} \mathrm{E}\right)$. She et al. (2002) and Arnold and She (2003) have described this Na lidar in detail. The set-up and status of the Na Lidar during December 2010 is described in more detail by Dunker et al. (2013). The Na lidar measures sodium number density, lineof-sight wind speed and temperature in the altitude range between about 80 and $110 \mathrm{~km}$ with uncertainties better than $10^{8} \mathrm{~m}^{-3}, 2 \mathrm{~m} \mathrm{~s}^{-1}$ and $2 \mathrm{~K}$, respectively. A cycle of three frequencies is emitted by the lidar, one at the $D_{2 a}$ frequency of sodium $(589.189 \mathrm{~nm})$ and the other two at $+630( \pm 50)$ and $-630( \pm 50) \mathrm{MHz}$, relative to the $D_{2 a}$ frequency. The emitted photons are resonantly scattered by the mesospheric sodium atoms, and the backscattered photons are collected with two telescopes $(\varnothing=1.8 \mathrm{~m})$ that belong to the ALOMAR Rayleigh/Mie/Raman lidar. The geophysical variables can be calculated from the recorded photon count profiles after integrating for one hour for each profile.

The ALOMAR Rayleigh-/Mie-/Raman (RMR) lidar uses two Nd:YAG lasers with a repetition frequency of $30 \mathrm{~Hz}$ and an energy of $\sim 400 \mathrm{~mJ}_{\text {pulse }}{ }^{-1}$ at $532 \mathrm{~nm}$ (von Zahn et al., 2000). The emitted wavelengths are at $1064 \mathrm{~nm}, 532 \mathrm{~nm}$ and $355 \mathrm{~nm}$. The atmospheric backscatter is recorded with two $1.8 \mathrm{~m}$ diameter Cassegrain telescopes that can be tilted up to $30 \mathrm{deg}$ off-zenith. Hydrostatic temperature profiles are calculated from relative density profiles obtained at $532 \mathrm{~nm}$ (Hauchecorne and Chanin, 1980). Densities are smoothed by a $1 \mathrm{~h}, 600 \mathrm{~m}$ window before temperature integration. Seed temperatures are taken from the MSIS model at an altitude of $90 \mathrm{~km}$. Seasonal temperature variations measured with the ALOMAR Rayleigh-/Mie-/Raman lidar along with a description of the analysis method can be found in Schöch et al. (2008). 


\subsection{MF-radar}

The Saura MF-radar is a Doppler radar that runs at $3.17 \mathrm{MHz}$ and is installed close to the Andøya Rocket Range as part of the ALOMAR observatory in Andenes.

Among other things, Saura MF radar measures mesospheric winds using the Doppler beam steering (DBS) technique. For this experiment, a total of 4 off-vertical beam directions are chosen, each at an angle of $6.8^{\circ}$ to the zenith and directed towards the northeast, southeast, southwest and northwest.

The main feature of this radar is the antenna which is formed by 29 crossed half-wave dipoles arranged as a MillsCross. The spacing of the crossed dipoles is 0.7 wave lengths resulting in a minimum beam width of $6.4^{\circ}$. Each dipole is fed by its own transceiver unit with a peak power of $2 \mathrm{~kW}$ (phase controlled on transmission and reception) providing high flexibility in beam forming and pointing as well as oand $\mathrm{x}$-mode operation for differential absorption and phase measurements (Singer et al., 2008; Singer et al., 2011).

\subsection{MLS satellite-borne instrument}

The Earth Observing System (EOS) Microwave Limb Sounder (MLS), onboard the National Aeronautics and Space Administration (NASA) Aura satellite uses the microwave limb sounding technique (Waters, 1993) to provide information on Earth's upper stratosphere and mesosphere.

The satellite rounds the Earth 15 times per day. For our purpose we focus on the temperature data in the vicinity of our launch area for 19 December 2010. The advantage of MLS is a good spatial coverage of measurements in large height range (i.e., from 50 to $100 \mathrm{~km}$ ). The vertical resolution of this technique is 3 to $6 \mathrm{~km}$ depending on altitude (Livesey et al., 2007; Wu et al., 2003) which is enough to detect largescale MILs.

\section{Experimental results}

In this paper, we focus on experimental results obtained during the last rocket flight conducted during ECOMA sounding rocket project (see e.g., Rapp et al., 2011, for more details) labelled ECOMA09.

The final sounding rocket campaign ECOMA-2010 took place from 19 November to 19 December 2010 at the north-Norwegian Andøya Rocket Range $\left(69^{\circ} \mathrm{N}, 16^{\circ} \mathrm{E}\right)$. During this campaign three instrumented sounding rockets were launched, namely, ECOMA07 on 4 December 2010, ECOMA08 on 13 December 2010, and ECOMA09 that was launched on 19 December 2010 at 02:36 UTC.

\subsection{In situ temperature measurements}

In situ measurements performed during the downleg of the ECOMA09 flight provided simultaneous and high-resolution measurements of neutral air densities, temperatures and turbulence.

The temperature profile obtained using the CONE sensor between 70 and $110 \mathrm{~km}$ is shown in Fig. 1a in black. The lowest temperatures of $\sim 175$ to $190 \mathrm{~K}$ appear at heights between 79 and $84 \mathrm{~km}$. The measured temperature profile reveals two pronounced temperature perturbations at heights between 71 and $74 \mathrm{~km}$ and between 86 and $89 \mathrm{~km}$, respectively. The amplitude of the upper perturbation, i.e., at 86 to $89 \mathrm{~km}$, reaches values of $44 \mathrm{~K}$ and is $3 \mathrm{~km}$ thick. The lower perturbation is somewhat weaker, i.e., it has an amplitude of $20 \mathrm{~K}$ and a thickness of $3 \mathrm{~km}$. The entire temperature profile, including regions with the temperature perturbations, also reveal clear signatures of gravity waves. These observed gravity waves, are also seen in the lidar data. They are created by orography in the lower atmosphere, and propagate upwards with increasing amplitude. Finally they break in the upper atmosphere, being one of the sources of the turbulence.

In Fig. 1a we also compare the CONE measurements with temperatures obtained using the ground-based lidars. The results of temperature measurements with the RMR- and Nalidars are shown as orange and blue profiles interrupted at $\sim 82 \mathrm{~km}$ height. That is, above $\sim 82 \mathrm{~km}$ the profiles represent Na-lidar measurements and below that height, the measurements by the RMR-lidar. The orange profile shows the data from the time of the ECOMA09 flight averaged over $30 \mathrm{~min}$, whereas the blue profile shows an eight hours mean from the day of the rocket launch.

The lidar measurements reveal very similar wave structures to those measured with the CONE. The small differences between the lidar and the in situ temperature measurements can likely be attributed to horizontal distance of $\sim 50 \mathrm{~km}$ between the lidar beam, that was pointing towards the direction of the rocket's ascent, and the volume probed by CONE on the descending part of the trajectory. Additionally, a reference profile from the MSISE-90 model (Hedin, 1991) is shown in Fig. 1a as the green line.

The two major temperature perturbations described above are clearly seen in both the in situ measurements and the 30min integrated lidar profile and are reminiscent of temperature inversion layers. However, it is not possible to qualify these temperature perturbations as inversion layers only based on single profiles. However, the 8-h mean profile obtained from the Na-lidar measurements, i.e., the upper part of the blue line, ultimately suggests that a mesospheric inversion layer (MIL) was caught by the in situ measurements, because this temperature enhancement clearly persists even after averaging over eight hours. For this reason, hereafter we will refer to the upper temperature enhancement as to the upper MIL. The time evolution of both temperature perturbations is further investigated in the next section utilising the lidar measurements. We also did the averaging of the lidar temperature over the whole day and over the second part of the day only (not shown here). They do not agree with CONE data as good as the averaged temperature from the first part 

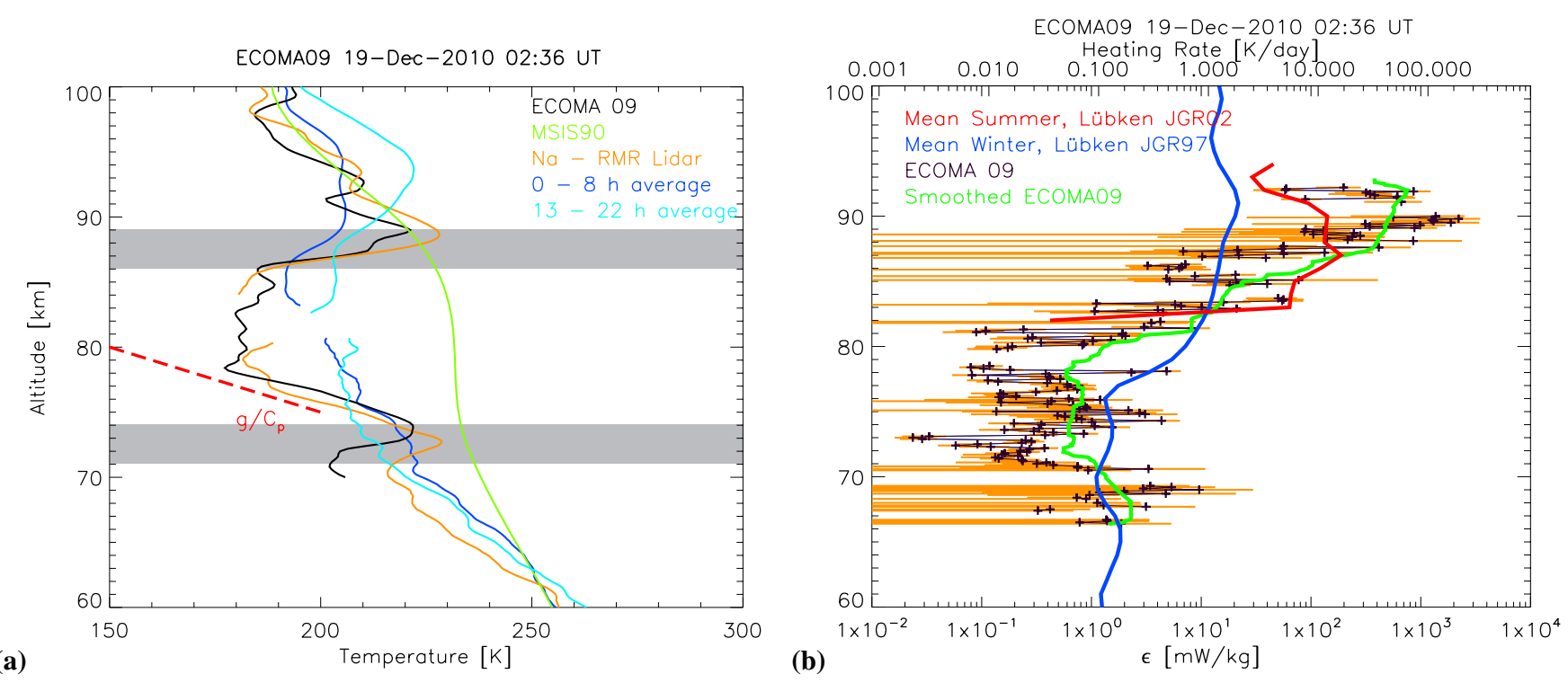

Fig. 1. (a) Neutral temperatures measured during the ECOMA09 flight (black line). Climatologies MSISE-90 is shown as green line. ALOMAR RMR - Na lidar measurements are plotted with orange line, with a gap between 81 and $84 \mathrm{~km}$ where no measurements were available. The dashed red line shows adiabatic lapse rate (please see text for details). Altitude ranges where MIL where observed are shaded. (b) Turbulence energy dissipation rates (and corresponding heating rates on upper abscissa) measured in situ during ECOMA09 flight (black crosses). Mean summer and winter profiles taken from Lübken et al. (2002) and Lübken (1997) are shown in red and blue, respectively. The high resolution $\varepsilon$-measurements were smoothed over $5 \mathrm{~km}$ to compare to the summer and winter "climatologies".

of the day, MIL exhibits there in the higher altitudes. This agrees with our conclusions that the observed MIL was the local enhancement of the temperature caused by turbulence inside of the larger and long persisting MIL.

At heights between 74 and $79 \mathrm{~km}$, i.e., right above the lower temperature enhancement and, at the same time below the upper MIL, the measured temperature profiles reveal an adiabatic to super-adiabatic lapse rate (compare with the adiabatic lapse rate shown by the red dashed line in Fig. 1a). Also, above the upper MIL, i.e., at heights between 89 and $95 \mathrm{~km}$, the measured temperatures reveal an adiabatic gradient. These gradients are suggestive of turbulence activity in those regions and have repeatedly been observed at the topside of the inversion layers (Whiteway et al., 1995; Duck et al., 2001).

The lower MIL looks more similar to the many lidar observations and resembles much the temperature and turbulence structure and adiabatic layer reported in Lehmacher and Lübken (1995), although with even lower epsilon values.

\subsection{Lidar temperature measurements}

In this section, we consider the time development of the temperature field to see whether the in situ observed temperature enhancements are indeed snapshots of inversion layers or simply represent large gravity wave amplitudes.

Figure 2 shows combined results of temperature measurements done simultaneously by the RMR- and sodium resonance lidars during the day of the ECOMA09 rocket launch.
The upper abscissa shows temperature for the first profile and the other profiles are shifted by $25 \mathrm{~K}$ and represent subsequent measurements in $30 \mathrm{~min}$ intervals to allow us to see the time evolution of the temperature enhancements. The lower abscissa shows time in UTC when the measurement was done. The bold profile represents the measurements done at $\sim 02: 36 \mathrm{UT}$, that is at the time of the ECOMA09 launch. The integration time for each shown profile is $1 \mathrm{~h}$. The dotted profiles shown in Fig. 2 represent the MSIS90 model and the dashed are the climatology by Lübken (1999) which is based on a large number of falling sphere (FS) measurements (Schmidlin, 1991). As in Fig. 1a, the upper part of the profiles in Fig. 2 represents measurements done with the Nalidar, whereas the lower part, i.e., below $\sim 82 \mathrm{~km}$, shows the RMR-lidar observations.

As it is seen in Fig. 2, the upper MIL, i.e., between 86 and $89 \mathrm{~km}$, was observed by the ALOMAR sodium resonance lidar for several hours around the rocket launch as it was already seen from the 8-h mean temperature profile in Fig. 1a. This MIL was already detected at $\sim$ 00:00 UT between $\sim 88$ and $92 \mathrm{~km}$ and descended during the period of at least $4 \mathrm{~h}$, however, afterwards its behaviour is not clear due to larger uncertainties between $\sim 82$ and $\sim 85 \mathrm{~km}$. Then, at 05:00 UT there is already a new MIL formed at $\sim 95 \mathrm{~km}$ which propagates downward with the similar rate. The maximum amplitude of the MIL in the Na-lidar data was $\sim 50 \mathrm{~K}$ and thickness of $8 \mathrm{~km}$.

The measurements in Fig. 2 also reveal that the lower temperature perturbation (i.e., between 74 and $79 \mathrm{~km}$ height), 


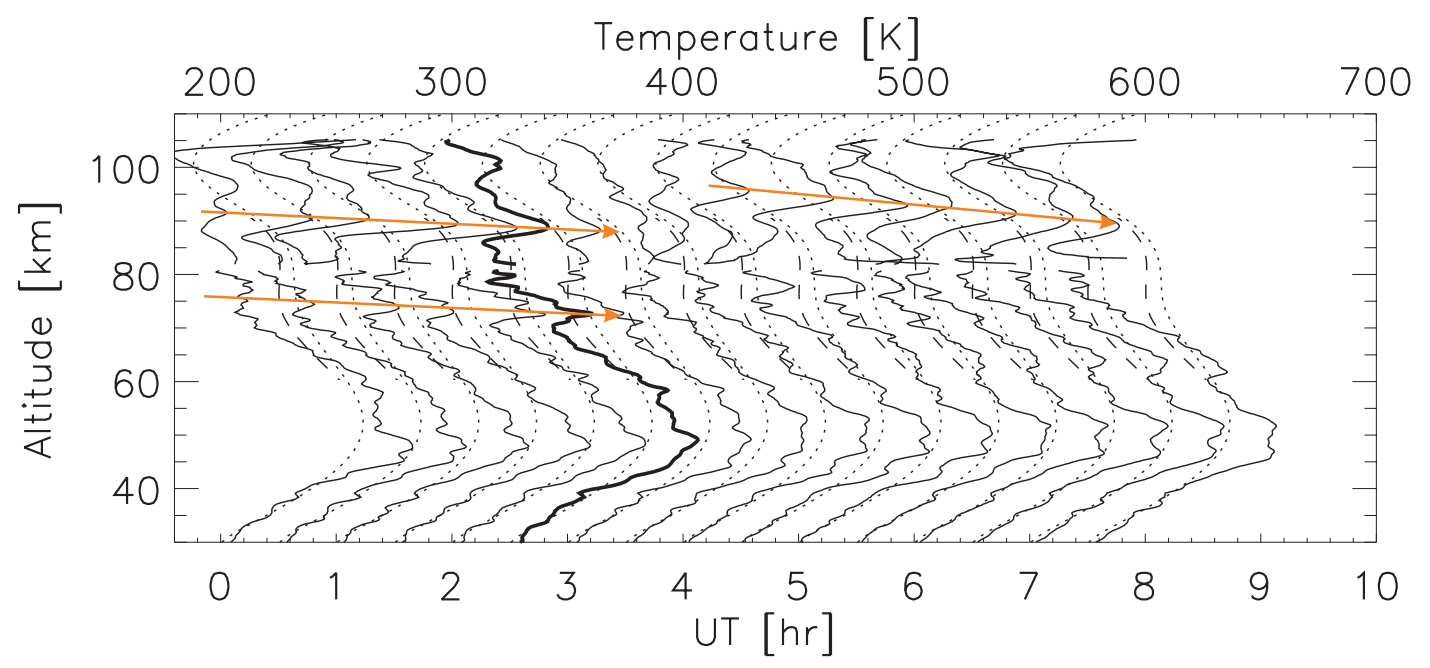

Fig. 2. Combined RMR and sodium resonance lidar temperature profiles for first eight hours of 19 December 2010 obtained from ALOMAR observatory. The profiles are averaged over one hour period. Please note the temperature perturbation downward progression denoted with the orange arrows.

with amplitudes of up to $20 \mathrm{~K}$ and a few kilometres thickness, is observed for a few hours before and about an hour after the rocket launch. The RMR-lidar started to measure on 18 December at 23:37:30 UTC, that is three hours before the rocket launch and the lower temperature perturbation was already there as detected by the lidar. Based on this relatively long duration $(\sim 3 \mathrm{~h})$ we qualify this lower temperature enhancement also as a MIL. The measured temperature profiles also reveal oscillations with smaller amplitudes associated with short period gravity waves.

In Fig. 2 one can see a downward phase progression of both MILs which is marked by the arrows. Using simple analysis e.g., applied by Dao et al. (1995), that is by fitting a polynomial to the temperature profiles and looking on the temperature maxima, one can find that the upper MIL (86 to $89 \mathrm{~km}$ at the time of the rocket launch) descends approximately at a rate of $15 \mathrm{~km}$ per $12 \mathrm{~h}$. The lower MIL descends with the same speed and is located $\sim 15 \mathrm{~km}$ below the upper one.

\subsection{Satellite temperature measurements}

Figure 3 shows temperature measurements obtained with the MLS over the rocket launch site close to the time of the ECOMA09 flight. Two temperature transects taken over Scandinavia were chosen. In the right panel of Fig. 3 transects geometries are shown by black arrows.

The red stars mark points where individual profiles were retrieved and revealed an inversion layer. The green diamond shows the location of the Andøya Rocket Range. The upper and the lower left panels show the temperature field as observed by the MLS along the track 1 and 2, respectively. The launch site is also denoted on the lower left panel by the vertical orange line.
From these observations it is clearly seen that the upper MIL detected by the rocket-borne instruments and the ground-based Na-lidar near the island of Andøya extents over at least $3000 \mathrm{~km}$ along the track 2 . Since such a huge spatial extension of the temperature enhancement is typical feature of the MILs (e.g., Meriwether and Gerrard, 2004), this ultimately confirms that we observed the temperature inversion layer between 86 and $89 \mathrm{~km}$.

The MLS measurements reveal an amplitude of the upper MIL of about $20 \mathrm{~K}$ and a thickness of $\sim 10 \mathrm{~km}$. It is already known from previous studies (e.g., Wu et al., 2003), that the amplitude of the temperature inversion layers obtained from MLS measurements are significantly underestimated in comparison with e.g., lidar observations, due to its coarse altitude resolution. Also, due to poor resolution of MLS, the lower temperature perturbation observed both in situ and by the RMR-lidar was not detected by the satellite borne experiment.

\subsection{In situ turbulence measurements}

As was mentioned above, the unique advantage of our in situ measurements by the CONE, is that we measure neutral temperature and turbulence energy dissipation rates (that can be converted to heating rates) simultaneously, with high resolution and precision. The results of the turbulence measurements during the ECOMA09 flight are shown in the Fig. 1b.

The turbulence energy dissipation rates, $\varepsilon$ are shown in Fig. $1 \mathrm{~b}$ as black crosses with orange error bars. Our turbulence detection technique results in an effective altitude resolution of $100 \mathrm{~m}$ (Strelnikov et al., 2003). We also smoothed the derived $\varepsilon$-profile to achieve the resolution of the available mean summer and winter "climatologies" by Lübken et al. (2002) and Lübken (1997), respectively, which is $5 \mathrm{~km}$. The 




Fig. 3. Two transects of satellite MLS temperature measurements taken on 19 December 2010 over Scandinavia. For convenience transects are numbered both on plots and in the inset map with their direction denoted with arrows. Launch area is marked as an orange line on the lower plots and as green rectangle in the inset map. On the inset map parts of the transects over which MIL is observed are marked with red stars. Over each transect its start and end time is shown.

smoothed $\varepsilon$-profile is shown in Fig. $1 \mathrm{~b}$ as the green line. The mean summer and winter turbulence energy dissipation rates are shown in Fig. 1b by red and blue profiles, respectively.

The energy dissipation rate can be converted to heating rate as (e.g., Lübken, 1992) $\partial T / \partial t=\varepsilon / c_{p}$, where $c_{p}=$ $1004 \mathrm{~J}(\mathrm{~K} \mathrm{~kg})^{-1}$ is the specific heat capacity of air at constant pressure. The resultant heating rates are represented by the upper axis in Fig. $1 b$.

As one can see, turbulence was observed over a broad altitude range from $\sim 65$ to $93 \mathrm{~km}$, which is typical for the winter polar mesosphere (Lübken, 1997). Also, the absolute values are close to the mean winter state at altitudes below $87 \mathrm{~km}$. However, at altitudes around $90 \mathrm{~km}$ the energy dissipation rates measured during the ECOMA09 flight are extremely large and exceed even typical summer values.

It is interesting to compare the measured turbulence dissipation rates with the results of the temperature measurements shown in Fig. 1a. At heights of $\sim 75$ and $\sim 90 \mathrm{~km}$, i.e., on the topside of the two observed inversion layers, turbulence exhibits local maxima. Especially the upper MIL is accompanied by the extremely strong turbulence with a dissipation rate of $\sim 2 \mathrm{~W} \mathrm{~kg}^{-1}$ which is equivalent to a heating rate of $200 \mathrm{~K} \mathrm{day}^{-1}$. According to numerical simulations by Liu et al. (2000), turbulence characterized by a heating rate of $\sim 10 \mathrm{~K} \mathrm{~h}^{-1}$ (i.e., $240 \mathrm{~K} \mathrm{day}^{-1}$ ) is sufficient for producing inversion layers alone. However, in the model of Liu et al. (2000) dissipative heating rate itself is insignificant when compared with the rate of heating due to turbulent diffusion. In the simpler model by Whiteway et al. (1995) the dissipation heating rate is much larger, exceeding in the upper part of MIL heating due to turbulent diffusion. The turbulent heating and cooling were parameterised in this model in terms of the eddy diffusion coefficient for heat transport, $K_{\mathrm{h}}$. For the region with MIL heating due to dissipation of $20 \mathrm{~K} \mathrm{day}^{-1} \mathrm{oc}-$ curred. This model is set, however, in the region were lower MILs occurring.

In the region around $69 \mathrm{~km}$, it also exhibits peak in turbulence data, with the values exceeding the values of the turbulence associated with the lower MIL. However, no MIL exhibits at this altitude. The source of this turbulence is either wind shear or GW breaking. The wind data are not available for this altitude, so it is not possible to investigate the latter.

Note also, that our turbulence detection technique is not sensitive to turbulence in the regions where the temperature profile exhibits an adiabatic lapse rate (e.g., Lehmacher and Lübken, 1995) and, therefore, can underestimate the actual $\varepsilon$-values. This implies that the turbulence dissipation above the inversion layers could be even stronger than what we observed with the CONE instrument.

\subsection{Na-lidar and radar wind measurements}

As described in Sect. 2.2, the ALOMAR Na resonance lidar is capable of measuring horizontal winds. The results of the 


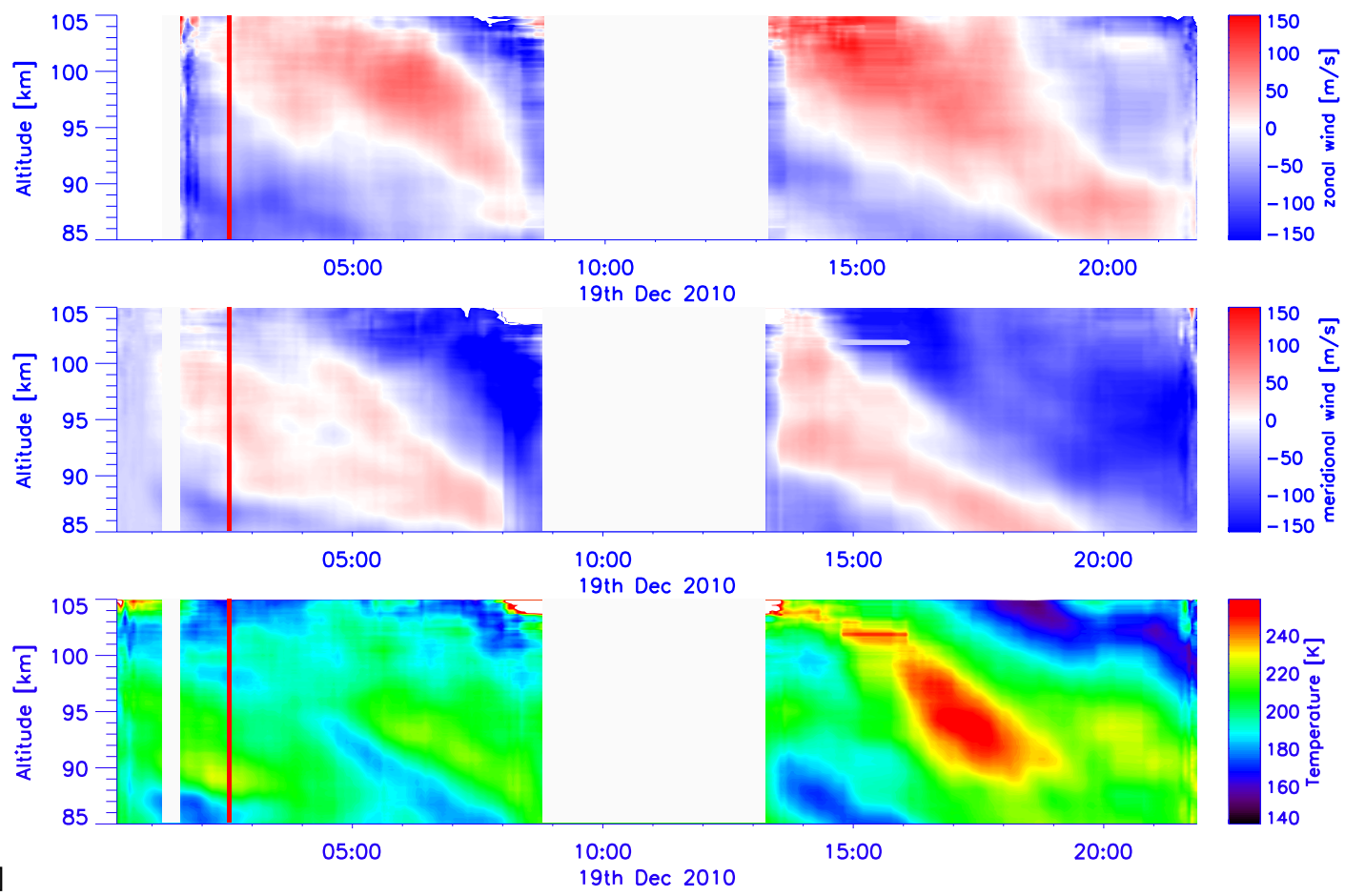

Fig. 4. Zonal (upper panel) and meridional (middle panel) winds and temperatures (lower panel) as measured by the Alomar Na-lidar on 19 December 2010. The blank areas on the plots mark the periods where no data were available. With red vertical line launch time of the third ECOMA rocket is marked.

lidar wind measurements during the day of the rocket launch are shown in Fig. 4.

It shows measurements of zonal winds, meridional winds and temperatures in the top, middle and lower panels, respectively. These measurements reveal pronounced downward phase progression which is most probably associated with tides Hoffmann et al. (2008); Stevens et al. (2010); Hultgren et al. (2011). Since lidar measurements are weather dependent and there was no luck to have long enough measurements for proper tidal analysis, we further consider wind measurements done by the Saura MF radar which is located close to the launch site (see Sect. 2.3).

The zonal and meridional wind measurements made by the Saura MF radar are shown in the upper and lower panel of Fig. 5, respectively. One can see the same downward phase progression as in the lidar observations (Fig. 4, two upper panels). The radar measurements cover a time period of several months around the rocket launch time which, in turn, makes it possible to perform deeper analysis with respect to tidal activity in the MLT region.

The wind measurements by SAURA MF radar during the entire month (December) were analysed with respect to the dominating wave activities at heights between 82 and $~$ $100 \mathrm{~km}$. This analysis showed that a $12 \mathrm{~h}$ wave in both zonal and meridional wind measurements was dominating over the time period from 18 to 24 December. This is demonstrated by the wavelet power spectra shown in Fig. 6, where power
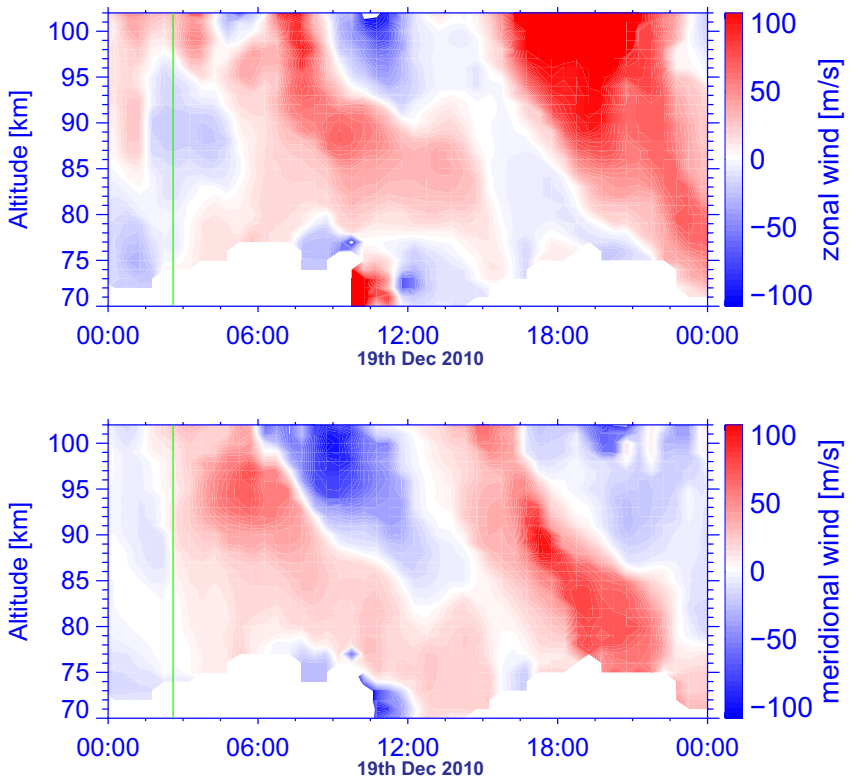

Fig. 5. One day snapshot of wind measurements by Saura MF radar. Upper panel: zonal wind. Lower panel: meridional wind. The green line marks time of the ECOMA09 launch.

spectrum for zonal and meridional wind components taken at $90 \mathrm{~km}$ height are shown in upper and lower panel, respectively. The horizontal dashed orange lines mark periods of 


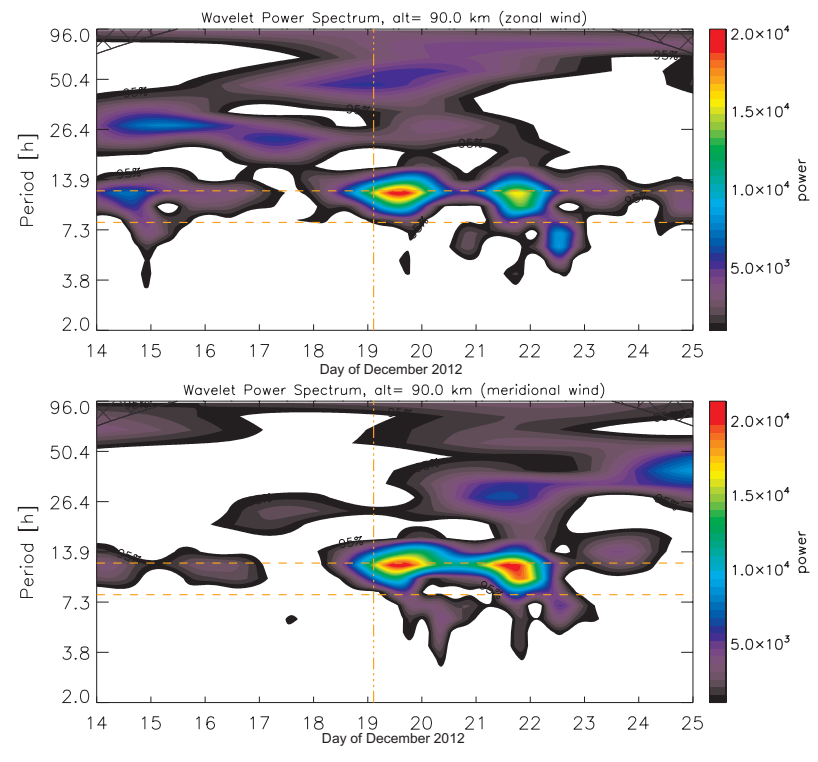

Fig. 6. The wavelet spectra of the the wind measured by the SAURA MF radar during December 2010. Upper panel: zonal wind. Lower panel: meridional wind. Horizontal orange lines mark 12 and $8 \mathrm{~h}$ periods. Vertical lines mark launch time of ECOMA09 sounding rocket. Cross hatched areas mark cone of influence, i.e., uncertain part of the spectra affected by edge effects.

12 and $8 \mathrm{~h}$ and the vertical lines show time of the ECOMA09 launch. It can be seen that although a signature of the semidiurnal tide is present during the entire period from 18 to 24 December, the strongest activity of the $12 \mathrm{~h}$ wave was observed from 19 through 22 December.

\section{Discussion}

Our discussion has to address two different formation mechanisms of the upper MIL. The first was initially proposed by Whiteway et al. (1995) and basically explains the formation of MIL by turbulent heating. The second goes back to Dao et al. (1995) and was summarized e.g., by Meriwether and Gardner (2000) and explains the formation of a MIL via the interaction of tides with gravity waves. Both these scenarios are discussed in detail e.g., in the review article by Meriwether and Gerrard (2004).

The adiabatic temperature gradient above both inversion layers detected in our case has been repeatedly observed by lidars (e.g., Whiteway et al., 1995; Thomas et al., 1996; Cutler et al., 2001; Duck and Greene, 2004; Liu et al., 2004; Collins et al., 2011) and has most often been the only argument regarding turbulence activity associated with temperature inversions. However, Thomas et al. (1996) performed simultaneous observations of MILs with Rayleigh lidar and mesospheric echoes with VHF radar and concluded that both dynamic and convective instabilities (and, therefore, the generated turbulence) are associated with these phenomena.
Moreover, they found that the radar echoes occurred both above and below the temperature maxima of the MILs. Our simultaneous in-situ measurements of both temperature and turbulence do not only confirm that point, but also allow to investigate the morphology of the MLT turbulence in connection with the thermal structure.

The upper MIL observed in our case by in-situ and Nalidar soundings between 86 and $89 \mathrm{~km}$ was accompanied by extremely strong turbulence. The highest values of the energy dissipation rates, $\varepsilon \approx 2 \mathrm{~W} \mathrm{~kg}^{-1}$, were detected between 89 and $90 \mathrm{~km}$ height, that is on top of the MIL. Also, turbulence was detected almost continuously in the entire height range of this MIL ( 86 to $89 \mathrm{~km}$ ). However, already at heights between 88 and $89 \mathrm{~km}$ the energy dissipation rate is an order of magnitude smaller than $1 \mathrm{~km}$ above. Moreover, this gradient in the $\varepsilon$ height-profile persists down to the bottom of the MIL, i.e., to $86 \mathrm{~km}$ altitude. So the energy dissipation rate increases by 3 orders of magnitude inside the inversion layer within only $3 \mathrm{~km}$ height range from 86 up to $89 \mathrm{~km}$. The largest measured $\varepsilon$-values of $2 \mathrm{~W} \mathrm{~kg}^{-1}$ corresponds to a heating rate of $\sim 200 \mathrm{~K} \mathrm{day}^{-1}$ is close to the model results by Liu et al. (2000) who showed that a heating rate of $\sim 10 \mathrm{~K} \mathrm{~h}^{-1}$ $\left(240 \mathrm{~K} \mathrm{day}^{-1}\right)$ is sufficient to produce a thermal structure in the mesosphere commonly associated with MIL. However, as mentioned before, heating rates described in Liu et al. (2000) are produced mainly with the turbulent diffusion, with the rate of heating due to dissipative heating (shown here), being insignificant. In the simpler model by Whiteway et al. (1995) the dissipative heating exceeds the heating rate due to turbulent diffusion in the upper part of MIL.

Whiteway et al. (1995) emphasised that it is not the high value of turbulence dissipation rates that plays the key role in creating MILs, but the rapid increase of the dissipation with height, i.e., the vertical gradient of the $\varepsilon$-profile. This point is consistent with our high resolution turbulence measurements.

There are two sources of turbulence relevant for our study, namely wind shear and breaking of gravity waves. According to Fritts et al. (2003) shear instability causes turbulence confined to a narrow layer, whereas gravity-wave breaking causes turbulence progressing with the phase of the wave and can, therefore, spread over larger height range. Also, the effects of turbulence due to shear instability should be observed for longer time. On the other hand, numerical simulations by Fritts et al. (2003) show that turbulence layers produced by dynamical instabilities reveal maximum viscous dissipation rather in the middle of the layer, whereas thermal dissipation occurs at the edges. For a GW-breaking event such a spatial separation of the peak turbulent kinetic energy and thermal dissipation diminishes while the event develops in time.

We calculated the vertical shear of the horizontal wind $\left(\sqrt{(d u / d z)^{2}+(d v / d z)^{2}}\right)$ from the Na-lidar measurements for the time of the rocket launch and found a local maximum of $0.05 \mathrm{~s}^{-1}$ close to $90 \mathrm{~km}$ height. This would imply 
low values of Richardson number, $(R i)$ in this region, which is further confirmed by our stability analysis further below.

Our turbulence measurements revealed that turbulent kinetic energy dissipation occurred in a broad altitude range which is typical for a GW-breaking event. The maximum of the dissipation measured with the CONE lies just on the top of the upper inversion layer. The adiabatic lapse rate between 89 and $91 \mathrm{~km}$, i.e., above the upper MIL suggests that turbulence was active for some time before the rocket sounding. Also, lidar observations do not show any dominant GWfrequencies, but rather a broad spectrum of different frequencies that reveal large amplitudes (not shown here) and, therefore, can potentially break generating turbulence.

Thus, the morphology of the turbulent structures suggests that GW-breaking was an active source of turbulence. Also the wind shear was peaking around the upper part of the inversion layer. These results support the interpretation that turbulent heating was involved in the formation of the in-situ observed inversion layer.

Also, as noted by e.g., Liu et al. (2004), the net effect of turbulence activity on the thermal structure is heating below and cooling above. This should result in an inversion layer and an adiabatic temperature gradient on top similar to what we observe and what has been reported from a vast number of previous observations. So, associating the observed temperature enhancement between 86 and $89 \mathrm{~km}$ with turbulent heating, is consistent with our measurements.

This can further be investigated considering stability of the background atmosphere and by comparing it with the observed behaviour of the MILs. The simultaneous measurements of horizontal winds and temperatures makes it possible to derive both the Brunt-Väisälä (buoyancy) frequency, $N$, which characterises the convective or static stability of the background atmosphere and the $R i$ that can be used to identify dynamically unstable regions. The results are shown in Fig. 7 where the colour red shows regions with $N^{2}<0$ and dark and light blue areas represent $R i<1 / 4$ and $R i<1$, respectively. The $R i<1 / 4$ is a favourable condition for instability to start, whereas $R i<1$ describes still favourable condition for instability to persist (Woods, 1969). The two downward progressing upper MILs are marked by the black arrows similar to what shown in Fig. 2. It is seen that both the convective $\left(N^{2}<0\right)$ and dynamically $(R i<1 / 4)$ unstable regions reveal downward phase progression similar to those observed in the temperature and wind fields and also the upper MIL (between 86 and $89 \mathrm{~km}$ ).

There is, however, a zone in Fig. 7 marked with a black oval of a downward progressing unstable region which is not associated with a temperature enhancement, but rather with a near adiabatic laps rate below the inversion layer. The insitu measurements show that there was also some turbulence activity below the inversion layer.

The lower panel of Fig. 4 shows the same measurements as shown in the upper part of Fig. 2, but during the entire day of the ECOMA09 launch. This plot reveals that the up-

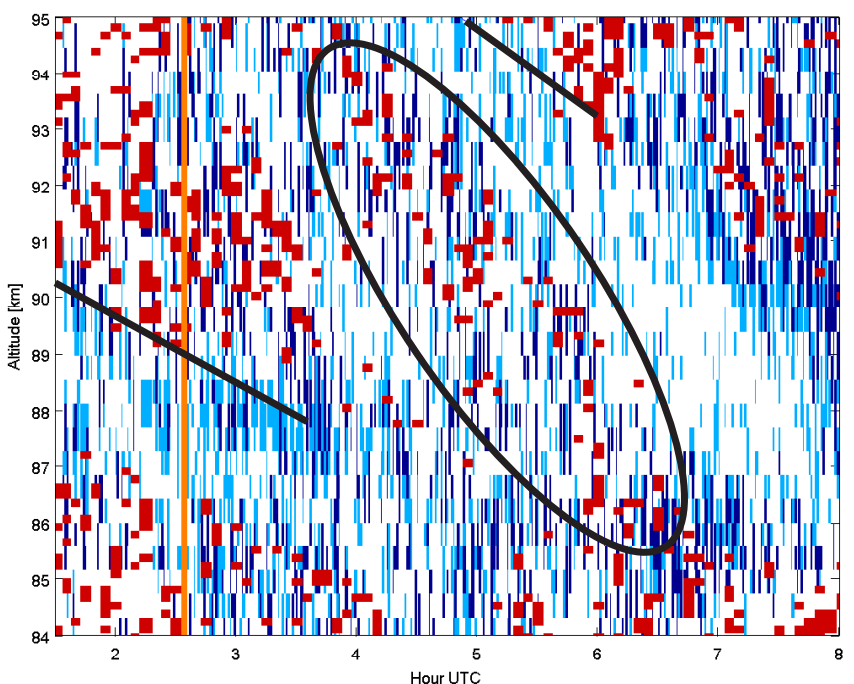

Fig. 7. Stability analysis from ALOMAR Na-lidar measurements of winds and temperature for 19 December 2010. The colour red represents regions that are convectively unstable $\left(N^{2}<0\right)$, dark blue points represent regions of dynamical instability $(0<R i<1 / 4)$, and the light blue areas are regions with $R i<1$. Orange vertical line marks time of the ECOMA09 launch.

per MIL observed by our rocket-borne instrument and that descended during next $\sim 3 \mathrm{~h}$, appeared three times during that day. These upper MILs descended at a very similar rate, however, as shown by two upper arrows in Fig. 2, that speed was not exactly the same. Also it was shown in Sect. 2.3 that strong semi-diurnal tidal activity was observed during the day of lidar and rocket measurements.

The MIL observed during ECOMA09, is already inside of strong tidal activity, but seems to be increased even further by the strong turbulence during this time.

One of the arguments against turbulence heating as an important physical process (e.g., Meriwether and Gardner, 2000 ) in development of the inversion layers was based on the mean dissipation values published by Lübken (1997) and Lübken et al. (2002). However, there are two points that have to be taken into account. The first is that the profile of the mean $\varepsilon$-values was smoothed over $5 \mathrm{~km}$. Also each single point represents an average of "turbulent" cases with some very high $\varepsilon$-values and even "non-turbulent" cases. When at a given height there was no turbulence, $\varepsilon$ was set to zero. The second point is that the vertical resolution of the analysis technique used for those turbulence "climatologies" had an altitude resolution of $1 \mathrm{~km}$. As was later shown by Strelnikov et al. (2003), applying a new analysis technique, the same measurements reveal a more structured $\varepsilon$-profile with regions of much higher $\varepsilon$-values, but in shorter than $1 \mathrm{~km}$ height ranges. A final argument by e.g., Duck and Greene (2004) was that the adiabatic lapse rate associated with inversion layers was not reported from rocket measurements by e.g., Lübken (1997). For the future, we will extend this 
type of study to infer more information about thermal structure and turbulence field.

It is interesting to note that satellite measurements with MLS show that the upper MIL appears over Andøya, i.e., the launch site, on 18 December and disappears after 24 December (not shown here). This is in line with the occurrence of the $12 \mathrm{~h}$ wave activity as shown in Fig. 6.

The lower MIL observed by our in-situ instrument and the RMR-lidar revealed the same descent rate as its upper counterpart and persisted for near the same time period (Fig. 2). The vertical separation of these layers was about $16 \mathrm{~km}$ which is too short for a vertical wavelength of tidal waves. The topside of this lower MIL is also accompanied by moderate local turbulence with relatively sharp gradients. Its morphology is very much reminiscent of GW-breaking event.

This analysis suggests that both MILs, i.e., between 71 and $73 \mathrm{~km}$ and between 86 and $89 \mathrm{~km}$, observed in situ were produced by strong turbulence which, in turn, developed due to the breaking of gravity waves. It is possible that both layers descend with the same tidal motion.

\section{Conclusions}

During the ECOMA09 sounding rocket flight we measured in situ a temperature profile that revealed two temperature enhancements, between 71 and $73 \mathrm{~km}$ and between 86 and $89 \mathrm{~km}$ altitudes. Simultaneously, the ALOMAR Weber Naand RMR-lidars observed the same temperature perturbations. The long duration lidar observations showed that this temperature perturbations persisted for several hours such that we qualified them as inversion layers (MILs). Additionally, satellite-borne observations with MLS showed that the upper MIL extended over an extended mesoscale region and lasted for 7 days which again confirms that this was a MIL. On the other hand, the lidar observations show that this MIL repeatedly appeared and descended during several hours which is not captured by the satellite instruments.

Similarities in the morphology of the turbulent layers with theoretical expectations for GW-breaking events and, also presence of the wind shear suggest that turbulent heating is a likely mechanism for the generation of the observed MILs.

However, our analysis cannot exclude the influence of tides and that the observed MILs resulted from a nonlinear interaction of tides and gravity waves as described by e.g., Meriwether and Gerrard (2004); Liu et al. (2000). However, our results ultimately show that if turbulence heating and downward heat transport were not the only mechanisms that generated the observed MIL, they at least significantly amplified the MIL.

Finally, we note that a series of rocket flights should be conducted during the temporal development of an inversion layer in order to monitor and better understand the role of turbulence during these various stages.
Acknowledgements. This work was supported by the German Space Agency (DLR) under grants 50 OE 0301 and 50 OE 0801 (Project ECOMA). The Aura MLS data product is available at NASA Goddard Earth Sciences Data and Information Service Center (GES-DISC; http://disc.gsfc.nasa.gov).

Topical Editor C. Jacobi thanks G. Lehmacher and one anonymous referee for their help in evaluating this paper.

\section{References}

Arnold, K. S. and She, C. Y.: Metal fluorescence lidar (light detection and ranging) and the middle atmosphere, Contemporary Physics, 44, 35-49, doi:10.1080/00107510302713, 2003.

Collins, R. L., Lehmacher, G. A., Larsen, M. F., and Mizutani, K.: Estimates of vertical eddy diffusivity in the upper mesosphere in the presence of a mesospheric inversion layer, Ann. Geophys., 29, 2019-2029, doi:10.5194/angeo-29-2019-2011, 2011.

Cutler, L. J., Collins, R. L., Mizutani, K., and Itabe, T.: Rayleigh lidar observations of mesospheric inversion layers at Poker Flat, Alaska (65deg N, 147deg W), Geophys. Res. Lett., 28, 14671470, doi:10.1029/2000GL012535, 2001.

Dao, P. D., Farley, R., Tao, X., and Gardner, C. S.: Lidar observations of the temperature profile between 25 and $103 \mathrm{~km}$ : Evidence of strong tidal perturbation, Geophys. Res. Lett., 22, 2825 2828, doi:10.1029/95GL02950, 1995.

Duck, T. J. and Greene, M. D.: High Arctic observations of mesospheric inversion layers, Geophys. Res. Lett., 31, L02105, doi:10.1029/2003GL018481, 2004.

Duck, T., Sipler, D., Salah, J., and Meriwether, J.: Rayleigh lidar observations of a mesospheric inversion layer during night and day, Geophys. Res. Lett., 28, 3597-3600, 2001.

Dunker, T., Hoppe, U.-P., Stober, G., and Rapp, M.: Development of the mesospheric $\mathrm{Na}$ layer at $69^{\circ} \mathrm{N}$ during the Geminids meteor shower 2010, Ann. Geophys., 31, 61-73, doi:10.5194/angeo-3161-2013, 2013.

Fritts, D. C., Bizon, C., Werne, J. A., and Meyer, C. K.: Layering accompanying turbulence generation due to shear instability and gravity-wave breaking, J. Geophys. Res., 108, 8452, doi:10.1029/2002JD002406, 2003.

Giebeler, J., Lübken, F.-J., and Nägele, M.: CONE - a new sensor for in-situ observations of neutral and plasma density fluctuations, ESA-SP-355, 311-318, 1993.

Hauchecorne, A. and Chanin, M.-L.: Density and temperature profiles obtained by lidar between 35 and $70 \mathrm{~km}$, Geophys. Res. Lett., 7, 565-568, doi:10.1029/GL007i008p00565, 1980.

Hedin, A. E.: Extension of the MSIS thermosphere model into the middle and lower atmosphere, J. Geophys. Res., 96, 1159-1172, 1991.

Hoffmann, P., Rapp, M., Fiedler, J., and Latteck, R.: Influence of tides and gravity waves on layering processes in the polar summer mesopause region, Ann. Geophys., 26, 4013-4022, doi:10.5194/angeo-26-4013-2008, 2008.

Hultgren, K., Körnich, H., Gumbel, J., Gerding, M., Hoffmann, P., Lossow, S., and Megner, L.: What caused the exceptional midlatitudinal noctilucent cloud event in July 2009, J. Atmos. SolarTerr. Phys., 73, 2125-2131, doi:10.1016/j.jastp.2010.12.008, 2011.

Lehmacher, G. and Lübken, F.-J.: Simultaneous observation of convective adjustment and turbulence generation in the mesosphere, 
Geophys. Res. Lett., 22, 2477-2480, doi:10.1029/95GL02351, 1995.

Liu, A. Z., Roble, R. G., Hecht, J. H., Larsen, M. F., and Gardner, S. C.: Unstable layers in the mesopause region observed with $\mathrm{Na}$ lidar during the Turbulent Oxygen Mixing Experiment (TOMEX) campaign, J. Geophys. Res., 109, D2, doi:10.1029/2002JD003056, 2004.

Liu, H.-L., Hagan, M. E., and Roble, R. G.: Local mean state changes due to gravity wave breaking modulated by the diurnal tide, J. Geophys. Res., 105, 12381-12396, doi:10.1029/1999JD901163, 2000.

Livesey, J. N., Read, W. G., Lambert, A., Cofield, R. E., Cuddy, D. T., Froidevaux, L., Fuller, R. A., Jarnot, R. F., Jiang, J. H., Jiang, Y. B., Knosp, B. W., Kovalenko, L. J., Pickett, H. M., Pumphrey, H. C., Santee, M. L., Schwartz, M. J., Stek, P. C., Wagner, P. A., Waters, J. W., and Wu, D. L.: Earth Observing System (EOS), Aura Microwave Limb Sounder (MLS), Version 2.2 Level 2 data quality and desription document, 2007.

Lübken, F.-J.: On the extraction of turbulent parameters from atmospheric density fluctuations, J. Geophys. Res., 97, 20385-20395, 1992.

Lübken, F.-J.: Seasonal variation of turbulent energy dissipation rates at high latitudes as determined by insitu measurements of neutral density fluctuations, J. Geophys. Res., 102, 1344113456, 1997.

Lübken, F.-J.: Thermal structure of the arctic summer mesosphere, J. Geophys. Res., 104, 9135-9150, doi:10.1029/1999JD900076, 1999.

Lübken, F.-J., Rapp, M., and Hoffmann, P.: Neutral air turbulence and temperatures in the vicinity of polar mesosphere summer echoes, J. Geophys. Res., 107, 4273-4277, doi:10.1029/2001JD000915, 2002.

Meriwether, J. W. and Gardner, C.: A review of the mesosphere inversion layer phenomenon, J. Geophys. Res., 105, 405-416, 2000.

Meriwether, J. W. and Gerrard, A. J.: Mesosphere inversion layers and stratosphere temperature enhancements, 42, RG3003, doi:10.1029/2003RG000133, 2004.

Rapp, M., Gumbel, J., and Lübken, F.-J.: Absolute density measurements in the middle atmosphere, Ann. Geophys., 19, 571-580, doi:10.5194/angeo-19-571-2001, 2001.

Rapp, M., Lübken, F.-J., Müllemann, A., Thomas, G. E., and Jensen, E. J.: Small scale temperature variations in the vicinity of NLC: Experimental and model results, J. Geophys. Res., 107, AAC 11-1-AAC 11-20, doi:10.1029/2001JD001241, 2002.

Rapp, M., Strelnikova, I., Strelnikov, B., Friedrich, M., Gumbel, J., Hoppe, U.-P., Blix, T., Havnes, O., Bracikowski, P., Lynch, K., and Knappmiller, S.: Microphysical Properties of Mesospheric Aerosols: An Overview of In Situ-Results from the ECOMA Project, vol. 2, pp. 67-74, Springer, the Netherlands, 2011.

Schmidlin, F. J.: Temperature inversions near 75 km, Geophys. Res. Lett., 3, 173-176, doi:10.1029/GL003i003p00173, 1976.

Schmidlin, F. J.: Derivation and application of temperature corrections for the United States radiosonde, in: Symposium on Meteorological Observations and Instrumentations, 7th, New Orleans, LA, 14-18 January 1991, Preprints (A92-32051 12-47). Boston, MA, American Meteorological Society, 1991, p. 227-231., pp. 227-231, 1991.
Schöch, A., Baumgarten, G., and Fiedler, J.: Polar middle atmosphere temperature climatology from Rayleigh lidar measurements at ALOMAR (69 N), Ann. Geophys., 26, 1681-1698, doi:10.5194/angeo-26-1681-2008, 2008.

She, C. Y., Vance, J. D., Williams, B. P., Krueger, D. A., Moosmuller, H., Gibson-Wilde, D., and Fritts, D.: Lidar studies of atmospheric dynamics near polar mesopause, EOS Transactions, 83, 289, doi:10.1029/2002EO000206, 2002.

Singer, W., Latteck, R., and Holdsworth, D. A.: A new narrow beam Doppler radar at $3 \mathrm{MHz}$ for studies of the highlatitude middle atmosphere, Adv. Space Res., 41, 1488-1494, doi:10.1016/j.asr.2007.10.006, 2008.

Singer, W., Latteck, R., Friedrich, M., Wakabayashi, M., and Rapp, M.: Seasonal and solar activity variability of D-region electron density at $69^{\circ}$ N, J. Atmos. Solar-Terr. Phys., 73, 925-935, doi:10.1016/j.jastp.2010.09.012, 2011.

Stevens, M. H., Siskind, D. E., Eckermann, S. D., Coy, L., McCormack, J. P., Englert, C. R., Hoppel, K. W., Nielsen, K., Kochenash, A. J., Hervig, M. E., Randall, C. E., Lumpe, J., Bailey, S. M., Rapp, M., and Hoffmann, P.: Tidally induced variations of polar mesospheric cloud altitudes and ice water content using a data assimilation system, J. Geophys. Res., 115, D18209, doi:10.1029/2009JD013225, 2010.

Strelnikov, B., Rapp, M., and Lübken, F.-J.: A new technique for the analysis of neutral air density fluctuations measured in situ in the middle atmosphere, Geophys. Res. Lett., 30, 2052, doi:10.1029/2003GL018271, 2003.

Thomas, L., Marsh, A., Wareing, D., Astin, I., and Chandra, H.: VHF echoes from the midlatitude mesosphere and the thermal structure observed by lidar, J. Geophys. Res., 101, 867-878, 1996.

von Zahn, U., von Cossart, G., Fiedler, J., Fricke, K. H., Nelke, G., Baumgarten, G., Rees, D., Hauchecorne, A., and Adolfsen, K.: The ALOMAR Rayleigh/Mie/Raman lidar: objectives, configuration, and performance, Ann. Geophys., 18, 815-833, doi:10.1007/s00585-000-0815-2, 2000.

Waters, J. W.: Microwave limb sounding, Atmospheric Remote Sensing by Microwave Radiometry, 1993.

Whiteway, J. A., Carswell, A. I., and Ward, W. E.: Mesospheric temperature inversions with overlying nearly adiabatic lapse rate: An indication of a well-mixed turbulent layer, Geophys. Res. Lett., 22, 1201-1204, doi:10.1029/95GL01109, 1995.

Woods, J. D.: On Richardson's Number as a Criterion for LaminarTurbulent-Laminar Transition in the Ocean and Atmosphere, Radio Sci., 4, 1289-1298, doi:10.1029/RS004i012p01289, 1969.

Wu, D., Read, W., Shippony, Z., Leblanc, T., Duck, T., Ortland, D., Sica, R., Argall, P., Oberheide, J., Hauchecorne, A., She, P. K. C., and Krueger, D.: Mesospheric temperature from UARS MLS: retrieval and validation, J. Atmos. Solar-Terr. Phys., 65, 245-267, 2003. 